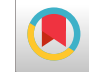

\title{
Investigating the Trend and Severity of Withdrawal Symptoms in Methamphetamine Users Amongst Homeless Addicts
} Yousef Khani, ${ }^{1}$ Hojatoolah Barati, ${ }^{1}$ Abolfaz Mollajan, ${ }^{1}$ Mahshid Mojtahedzadeh Faghihi, ${ }^{2}$ and Shahnaz $\operatorname{Rimaz}^{3, *}$

\author{
${ }^{1}$ Deputy of Health, Alborz University of Medical Sciences, Karaj, IR Iran \\ ${ }^{2}$ Department of Psychology, International Campus of Kharazmi University, Karaj, IR Iran \\ ${ }^{3}$ Department of Epidemiology, School of Public Health, Iran University of Medical Sciences, Tehran, IR Iran \\ "Corresponding author: Shahnaz Rimaz, Department of Epidemiology, School of Public Health, Iran University of Medical Sciences, Tehran, IR Iran. E-mail: \\ srimaz2000@yahoo.com
}

Received 2016 April 27; Revised 2017 February 15; Accepted 2017 April 24.

\begin{abstract}
Background: Determining the trend and severity of withdrawal symptoms is considered as the first stage of addiction treatment. Objectives: Therefore, The purpose of this study was to investigate the trend and severity of withdrawal symptoms in methamphetamine (meth) addicts.

Patients and Methods: This cross-sectional study was conducted on all the clients admitted to quit methamphetamine abuse in a residential treatment center for homeless addicts in Alborz province. According to the average daily intake, the clients were divided into two groups: mild and severe. To collect the data for this study; methamphetamine withdrawal symptoms assessment scale, Beck Depression Inventory (BDI) and a demographic information questionnaire were used. The analysis of variance (ANOVA) was done for repeated measures through the SPSS software version 16 and at a significance level of 0.05 .

Results: The findings showed that methamphetamine withdrawal symptoms including anxiety, abuse craving, and fatigue in the first 24 hours and the first, the second, and the third weeks as well as the symptoms of depression within three weeks after the withdrawal began to decline significantly $(\mathrm{P}<0.0001)$. Following the analysis of variance (ANOVA) for repeated data and taking addiction severity index into account, it was observed that the difference between the two groups of mild and severe addicts was significant in terms of the trend and severity of methamphetamine withdrawal symptoms $(\mathrm{P}<0.0001)$.

Conclusions: The hardest stage to quit methamphetamine addiction was the first 24 hours after withdrawal with a downward trend; however, abuse craving especially in severe addicted group persisted even after the third week of withdrawal which could be a risk factor for recurrence and re-abuse. Thus, it was suggested that therapists were required to pay more attention to this issue in the treatment of this group of addicted individuals.
\end{abstract}

Keywords: Methamphetamine, Craving, Withdrawal, Depression

\section{Background}

The abuse of illicit and psychoactive drugs has turned into a common problem in today's world (1). In this respect, the global prevalence of methamphetamine abuse is $0.4 \%$ and it is ranked in the second place among these drugs (2). According to the office for combating drugs and crimes in the United Nations; only in 2008 , the production of methamphetamine stimulants has been 168 to 588 tons (3). The report released by this office in 2014 also indicated that the abuse of methamphetamine compounds was as a growing global epidemic. According to this report, the number of laboratories producing methamphetamine compounds has increased from 12567 cases in 2011 to 14322 cases in 2012. This report has also introduced Iran among the nations with an upward trend of drug abuse and pro- duction of amphetamine compounds in a way that discovery of illicit ephedrine used to produce such substances in Iran has grown from $2378 \mathrm{~kg}$ in 2010 to $3809 \mathrm{~kg}$ in 2011 (4). Today's challenge to Iran is the changing patterns of drug abuse from traditional to industrial substances. This phenomenon demands a new reaction of its kind because industrial substances, unlike traditional ones, are not imported from specific geographic boundaries but they can be produced in small laboratories even in homes (5). According to the latest statistics and the results of the rapid situation assessment (RSA) of drug abuse in Iran, the frequency of Iranian methamphetamine addicts was reported by 5.3\% out of the total number of drug abusers (6). Moreover, the prevalence of the abuse of this substance based on other studies was about $18.5 \%$ in the 
youth aged 15 to 25 years in Tehran (7), 4.3\% among university students in the cities of Birjand and Gilan $(8,9)$, and $0.18 \%$ in college students in Hamadan (10). There are several reasons for the increase methamphetamine abuse such as rising costs of traditional opioids, lower price of industrial stimulants, and easy access to these substances $(11,12)$. Research studies have also revealed that the abuse of this illicit drug can lead to specific behavior patterns such as depression, sleep disorders, seizures, and aggressive behaviors (13). As Brechet et al. argued, $50 \%$ of patients who stopped methamphetamine abuse experienced recurrence and came back to the cycle of addiction to this drug. This recurrence took place in $36 \%$ of cases during the first 6 months after withdrawal (14). Other research studies have highlighted physiological dependence and abuse craving as two important factors affecting relapse and return to the cycle of addiction among recovered individuals (15-17). Despite the widespread and illicit use of methamphetamine compounds as well as the problems associated with them, only a few patients have asked for help from medical centers up until now. Reluctance to receive treatment could be due to the belief that treatment centers and their programs have been just for opioid-like substance abusers and they have given no help in terms of changes and treatments in their abuse manner $(18,19)$. Deficiencies in the management of withdrawal symptoms during treatment may cause a lot people abandon treatment on the first few days or weeks after withdrawal (14). A better understanding of the natural process and the symptoms of methamphetamine withdrawal can help in preventing its recurrence $(20,21)$. Therefore, the first important stage in an effective treatment is to determine the duration and severity of withdrawal symptoms. Checking this information will also facilitate the timely implementation of appropriate interventions (22).

\section{Objectives}

Given the mentioned issues and considering that there have been limited studies in terms of the natural process of methamphetamine abuse in Iran to date, the purpose of this study was to determine the trend and severity of withdrawal symptoms in methamphetamine-addicted clients in a residential treatment center for homeless addicts in Alborz province in 2014.

\section{Patients and Methods}

This cross-sectional study was conducted in a residential treatment center for homeless addicts in Alborz province. The statistical population of this study included all patients over 15 years old with observed methamphetamine in their urine detected by rapid diagnostic kits during the study period and at the moment of admission to the center as well as meeting diagnostic criteria (DSM-IV) for addiction to methamphetamine compounds and addicted only to this substance $(\mathrm{N}=100)$. The clients with psychosis or serious medical illnesses, individuals in need of psychotherapy, or those addicted to drugs other than nicotine were excluded from this study. Based on the average daily intake (in grams), the clients were divided into two groups: mild (with a consumption level below the average) and severe (with an intake level higher than the average) (23).

\subsection{Data Collection Instrument}

Three questionnaires were used to collect the data: 1 , a demographic questionnaire which included patients' general information such as age, gender, level of education, etc.; 2, Persian version of amphetamine cessation symptom assessment (ACSA) questionnaire. The original version of this questionnaire is designed by McGregor et al. (24). This questionnaire developed with 16 items to assess symptoms such as abuse craving, fatigue, restlessness, lack of a sense of joy, confusion, anxiety, sleeplessness, nightmare, and slow movements in which the items were rated based on a Likert-type scale ranging from 1 (not at all) to 5 (very high). The total score for this questionnaire was between 16 and 80 and higher scores meant more severity of withdrawal symptoms. Moreover, this questionnaire was composed of three dimensions of anxiety and mood, fatigue, and abuse carving. A Persian-version of the ACSA questionnaire was translated from English and proofed using the backward-forward translation method (25). To explore the face validity of the questionnaire, 10 experts provided direction for the writing, translating and arrangement of questions. A group discussion was facilitated through individual sessions where amphetamine withdrawal symptoms were discussed and the questionnaire was provided before administration, content validity index (CVI), factor analysis and principal component analysis were used to assess construct validity and validation the Persian version of questionnaire (26). For this purpose questionnaire was reviewed and confirmed by researchers and professors working in this field. Cronbach's alpha was used to assess the internal reliability of the questionnaire. That reliability of the questionnaire was also equal to $84 \%$. This questionnaire was completed 24 hours after withdrawal on a daily basis for 21 days; and 3. Beck depression inventory which has been commonly used in various studies. It was a 21-item questionnaire with four-choice answers rated from 0 to 3 on a Likert-type scale. Accordingly, it divided individuals into five groups of without depression, 
mild depression, moderate depression, severe depression, and very severe depression. This inventory was completed during the first, the second, and the third weeks of treatment.

To conduct this study, necessary coordination was made with officials from a residential treatment center for homeless addicts in Alborz province. Likewise; after the explanation of the objectives of the study, an informed consent form was completed by participants. To administer the questionnaires, two trained investigators were recruited and took part in a training session on how to complete them. The SPSS software version 16 was also used to analyze the data. Demographic information and data on the amount and duration of abuse among individuals were investigated using descriptive methods. Then, the means and standard deviations for the first day, the seventh day, the fourteenth day, and the twenty-first day were calculated separately for groups. To examine the changes in the means of the severity of symptoms over three weeks as well as the differences in the severity of symptoms in groups, analysis of variance (ANOVA) for repeated data at a significance level of 0.05 was used.

\section{Results}

The average daily intake of methamphetamine in patients was 1.675 grams. According to this indicator, these addicts were divided into two groups: severe addicts (taking over 1.675 grams per day) and mild ones (less than 1.675 grams per day). All the participants in the study were male and smokers. The demographic characteristics of the participants in this study are presented in Table 1.

The results of this study showed that methamphetamine withdrawal symptoms including anxiety, abuse craving, and fatigue in both mild and severe groups were observed in the first 24 hours, the first week, the second week, and the third week; and depression symptoms began to decline significantly within three weeks after withdrawal $(\mathrm{P}<0.0001)$. By conducting analysis of variance (ANOVA) for repeated data and considering addiction severity index in the analysis of the results, it was revealed that the difference between the two groups of mild and severe addicts was statistically significant in terms of the trend and severity of methamphetamine withdrawal symptoms $(\mathrm{P}<0.0001)$. These findings are shown in Table 2.

\section{Discussion}

According to the findings of this study, the mean for the total score of methamphetamine withdrawal symp- toms scale among the participants on the first day of withdrawal was the highest one and it significantly declined within three weeks $(\mathrm{P}<0.0001)$. These symptoms among severe addicts compared at the same time to mild addicted patients were at a higher level. The results of this study were somewhat consistent with those found by McGregor et al. They showed that methamphetamine withdrawal symptoms within the first 24 hours had the highest severity and then reduced within 7 to 10 days (23). In a study conducted in Iran by Bagheri et al. depression symptoms reduced after of withdrawal methamphetamine which was consistent with the results of our study. However, symptoms related to anxiety in that study did not change and in this respect not match by our study (27). In another similar study conducted by Taod Zorick et al., methamphetamine withdrawal symptoms had the highest severity within the first 24 hours and then declined within two weeks (28). Although, like other studies, methamphetamine withdrawal symptoms within the first 24 hours had the highest severity and then reduced over time in the present study; the decline in the severity of withdrawal symptoms took place at a slower rate so that the decreasing trend in severe addicts over three weeks was slower than that among the mild group and the withdrawal symptoms did not disappear even after this period. This would probably indicate that methamphetamine addicts in Iran required a longer treatment period.

Based on the results of the present study, craving for methamphetamine abuse during the first 24 hours after withdrawal was at a maximum level and then decreased gradually. Craving for methamphetamine had the highest severity on the first day of withdrawal and declined at the end of the second week; however, it did not fade away and temptation to methamphetamine abuse was observed at the fifth week following withdrawal. Craving for methamphetamine is a very important factor to quit this substance. That is, high craving rate for methamphetamine increases the likelihood of recurrence for this substance (29). So, as it was shown in a prospective study, craving rate of over $20 \%$ (on a scale of one hundred points) increased the relative risk of methamphetamine relapse up to two times (30). Thus, continued craving after methamphetamine withdrawal could be a risk factor for recurrence and reabuse. Since the results of this study showed that craving for methamphetamine especially in the severe group of addicts lasted even three weeks after withdrawal, the therapists of this group of addicts were required to pay more attention to this issue.

The issue of sleep, which was assessed in this study only by one item in the fatigue factor, has been investigated in some studies with a separate multiple-choice questionnaire considering several different dimensions such as du- 


\begin{tabular}{|c|c|c|c|c|}
\hline Variables & Mild Addicts & Severe Addicts & Statistic & PValue \\
\hline Age, mean (SD) & $27.50(6.538)$ & $32.60(5.443)$ & $\mathrm{T}=3.75$ & $<0.0001$ \\
\hline Level of education, No. (\%) & & & $X^{2}=4.76$ & $<0.029$ \\
\hline Below diploma & $52(74.3)$ & $28(93.3)$ & & \\
\hline Diploma and higher & $18(25.7)$ & $2(6.7)$ & & \\
\hline Employment status, No. (\%) & & & $X^{2}=28$ & $<0.004$ \\
\hline Employed & $33(47.1)$ & $5(16.7)$ & & \\
\hline Unemployed & $37(52.9)$ & $25(83.3)$ & & \\
\hline Marital status, No. (\%) & & & $X^{2}=13.15$ & $<0.001$ \\
\hline Single & $17(24.3)$ & $1(3.3)$ & & \\
\hline Married & $26(37.1)$ & $6(20)$ & & \\
\hline Divorced & $28(38.6)$ & $23(76.7)$ & & \\
\hline
\end{tabular}

ration of sleep, sleep continuity, sleep per night, daytime sleep, quality of sleep, depth of sleep, and satisfaction with sleep $(23,31)$. The results of this study were consistent with the findings by McGregor et al. (23) and Rawson et al. (31). In terms of duration of sleep. They found that drowsiness and sleep duration in these patients reduced over time and there was a significantly downward trend at the end of the twenty-first day. In these two studies; other dimensions of sleep including quality of sleep and depth of sleep were also investigated and it was found that although sleepiness and sleep duration in these patients became normal over time; the quality and depth of sleep among these patients was low even after three weeks, they slept late at night, and woke up more during sleep. However, these issues were not investigated in the present study. The results of this study were not in line with an investigation by Gosop et al. in which they found that the number of hours of sleep per night in methamphetamine abusers on the first 20 days after the withdrawal was significantly lower compared with that in the control group (20).

Beck depression inventory with 21 items was also used to review the natural process of depression symptoms among individuals quitting methamphetamine in this study. This questionnaire was completed on a weekly basis for three weeks by participants in the study. The results showed that the severity of depression symptoms significantly decreased in both groups after three weeks. Although there was a significant difference between the means of these two groups $(\mathrm{P}<0.001)$, depression symptoms were observed in severe addicted group even after the third week of withdrawal. This study was in agreement with the findings of McGregor et al. as well as Zordick et al. $(23,28)$. In which the severity of depression symp- toms in these patients declined over time. The main point to mention was that depression symptoms in their studies disappeared within 7 to 14 days, but it took more than three weeks in the present study to eliminate the symptoms of depression completely especially in severe addicts. These findings were consistent with the results of previous studies in which long-term depression occurred after withdrawal from methamphetamine $(31,32)$. Studies have also shown that methamphetamine-addicted patients were at higher risks for depression and suicide attempts (33). On the other hand, depression symptoms might not fully disappear due to short-term treatment period (34). Given that the symptoms of depression in this study persisted for a long time, it seemed that increasing the length of treatment particularly in terms of the relief of depression symptoms was helpful to this group of patients.

\subsection{Limitations and Suggestions}

All the participants in this study were male. Therefore it was recommended to conduct further studies on individuals inclined to quit drug abuse as well as female addicts in order to determine the trend and severity of methamphetamine withdrawal symptoms better. The results of this study demonstrated that withdrawal symptoms particularly depression and abuse craving persisted for over three weeks; thus, it was suggested to check depression and abuse craving as withdrawal symptoms in a long-term period. The variable of sleep was also assessed in this study only in one item in methamphetamine withdrawal symptoms assessment scale and it was better to study sleep status of these patients with specific and validated scales. 
Table 2. The Trend and Severity of Methamphetamine Withdrawal Symptoms, Anxiety and Mood, Abuse Craving, Fatigue, and Depression Using Analysis of Variance (ANOVA) for Repeated Data ${ }^{\mathrm{a}}$

\begin{tabular}{|c|c|c|c|c|c|c|}
\hline Variables & $\begin{array}{l}24 \text { Hours After } \\
\text { Withdrawal }\end{array}$ & $\begin{array}{l}\text { The First Week } \\
\text { After Withdrawal }\end{array}$ & $\begin{array}{l}\text { the Second Week } \\
\text { After Withdrawal }\end{array}$ & $\begin{array}{l}\text { the third Week } \\
\text { After Withdrawal }\end{array}$ & $\begin{array}{l}\text { Results of Analysis } \\
\text { of Variance } \\
\text { (ANOVA) for } \\
\text { Repeated Data }\end{array}$ & $\begin{array}{l}\text { Results of Analysis } \\
\text { of Variance } \\
\text { (ANOVA) for } \\
\text { Repeated } \\
\text { Measures Based } \\
\text { on Addiction } \\
\text { Severity Index }\end{array}$ \\
\hline $\begin{array}{l}\text { Total score for } \\
\text { metham- } \\
\text { phetamine } \\
\text { withdrawal scale }\end{array}$ & & & & & & $\mathrm{P}<0.001$ \\
\hline Mild addicts & $76.62(0.66)$ & $69.68(3.21)$ & $55.75(4.74)$ & $20.54(1.53)$ & $\mathrm{P}<0.001$ & \\
\hline $\begin{array}{l}\text { Severe } \\
\text { addicts }\end{array}$ & $75.86(0.34)$ & $71.13(2.64)$ & $65.40(3.38)$ & $48.40(1.16)$ & $\mathrm{P}<0.001$ & \\
\hline $\begin{array}{l}\text { Scores for the first } \\
\text { dimension of } \\
\text { metham- } \\
\text { phetamine } \\
\text { withdrawal scale } \\
\text { (anxiety and } \\
\text { mood symptoms) }\end{array}$ & & & & & & $\mathrm{P}<0.001$ \\
\hline Mild addicts & $54.75(0.50)$ & $49.14(2.53)$ & $37.95(4.32)$ & $11.42(1.01)$ & $\mathrm{P}<0.001$ & \\
\hline $\begin{array}{l}\text { Severe } \\
\text { addicts }\end{array}$ & $54.96(0.18)$ & $51.46(2.11)$ & $46.33(2.39)$ & $33.33(0.99)$ & $\mathrm{P}<0.001$ & \\
\hline $\begin{array}{l}\text { Scores for the } \\
\text { second dimension } \\
\text { of metham- } \\
\text { phetamine } \\
\text { withdrawal scale } \\
\text { (abuse craving) }\end{array}$ & & & & & & $P<0.001$ \\
\hline Mild addicts & $10(0.000)$ & $8.88(0.57)$ & $6.95(0.78)$ & $2.05(0.37)$ & $\mathrm{P}<0.001$ & \\
\hline $\begin{array}{l}\text { Severe } \\
\text { addicts }\end{array}$ & $10(0.000)$ & $9.23(0.97)$ & $8.36(0.80)$ & $5.93(0.36)$ & $\mathrm{P}<0.001$ & \\
\hline $\begin{array}{l}\text { Scores for the } \\
\text { third dimension } \\
\text { of metham- } \\
\text { phetamine } \\
\text { withdrawal scale } \\
\text { (fatigue } \\
\text { symptoms) }\end{array}$ & & & & & & $\mathrm{P}<0.001$ \\
\hline Mild addicts & $10.88(0.32)$ & $11.65(0.86)$ & $10.84(0.92)$ & $7.05(0.58)$ & $\mathrm{P}<0.001$ & \\
\hline $\begin{array}{l}\text { Severe } \\
\text { addicts }\end{array}$ & $10.90(0.30)$ & $10.43(1.22)$ & $10.70(0.79)$ & $9.13(0.34)$ & $\mathrm{P}<0.001$ & \\
\hline $\begin{array}{l}\text { Scores for Beck } \\
\text { depression } \\
\text { inventory }\end{array}$ & & & & & & $\mathrm{P}<0.001$ \\
\hline Mild addicts & - & $68.32(6.80)$ & $47.78(6.40)$ & $24.81(2.48)$ & $\mathrm{P}<0.001$ & \\
\hline $\begin{array}{l}\text { Severe } \\
\text { addicts }\end{array}$ & - & $79.13(1.88)$ & $70.70(3.27)$ & $51.16(0.87)$ & $\mathrm{P}<0.001$ & \\
\hline
\end{tabular}

${ }^{\mathrm{a}}$ Values are expressed as mean (SD).

\subsection{Conclusion}

Since the hardest stage in methamphetamine withdrawal was the first days of withdrawal particularly the first 24 hours according to the results of this study, it was necessary for addiction therapist to consider this issue in preventing the recurrence of abuse. Moreover, the results of this study revealed that withdrawal symptoms reduced over time but abuse craving for methamphetamine particularly in the severe addicted group persisted even within three weeks after they cut it off. It was concluded that 
if therapist do not pay attention to this issue, it can be an important risk factor affecting the recurrence of abuse among the recovered individuals.

\section{Acknowledgments}

This article was derived from a master's thesis at the school of public health in Tehran University of Medical Sciences. We express our gratitude to all the faculty members of department of epidemiology and biostatistics who helped us in this regard. This research study was conducted in cooperation with the staff and clients in a residential treatment center for homeless addicts in Alborz province in 2014. Thereby, we appreciated all of them.

\section{References}

1. Costa e Silva JA. Evidence-based analysis of the worldwide abuse of licit and illicit drugs. Hum Psychopharmacol. 2002;17(3):131-40. doi: 10.1002/hup.378. [PubMed: 12404690].

2. Cruickshank CC, Dyer KR. A review of the clinical pharmacology of methamphetamine.Addiction.2009;104(7):1085-99. doi:10.1111/j.13600443.2009.02564.x. [PubMed: 19426289].

3. United Nations Office on Drugs and Crime (UNODC). World Drug Report 2010. United Nations publication, Sales No E.10.XI.13; 2010.

4. United Nations Office on Drugs and Crime (UNODC). World Drug Report 2014. United Nations publication, Sales No. E.14.XI.7; 2014

5. Moharreri MR. General view of drug abuse in Iran, and a one-year report of out- patient treatment of opiate addiction in the city of Shiraz. The International Challenge of Drug Abuse. Rockville: NIDA Research Monograph 19; 1978.

6. Narenjiha H, Rafiey H, Baghestani AH. Rapid situation assessment of drug abuse and drug dependence in Iran. Tehran: Darius Institute; 2005.

7. Barooni S, Mehrdad R, Akbari E. A survey of Ecstasy use among 1525 year-olds in five areas of Tehran [In Persian]. Tehran Univ Med J. 2008;65(11):49-54.

8. Mohtasham-Amiri Z, Jafari-Shakib A, Khalili-Moosavi A. Prevalence and factors associated with Ecstasy use among college undergraduates in north of Iran-2005. Asian J Psychiatr. 2011;4(1):31-4. doi: 10.1016/j.ajp.2011.01.004. [PubMed: 23050911].

9. Moasheri N, Miri M, Mashreghi Moghadam HM, Eslami MR. A Study of Birjand University students' knowledge and attitude towards taking Ecstasy pills [In Persian].J Birjand Univ Med Sci. 2007;13(4):9-15.

10. Barati M, Allahverdipour H, Jalilian F. Prevalence and predictive factors of psychoactive and hallucinogenic substance abuse among college students [In Persian]. J Fund Ment Health. 2012;13(4):347-83.

11. Kulsudjarit K. Drug problem in southeast and southwest Asia. Ann N Y Acad Sci. 2004;1025:446-57. doi: 10.1196/annals.1316.055. [PubMed: 15542748].

12. Samii AW. Drug abuse: Iran's 'thorniest problem'. Brown J World Aff. 2003;9(2):283.

13. Murray JB. Psychophysiological aspects of amphetaminemethamphetamine abuse. J Psychol. 1998;132(2):227-37. doi: 10.1080/00223989809599162. [PubMed: 9529666].

14. Brecht ML, von Mayrhauser C, Anglin MD. Predictors of relapse after treatment for methamphetamine use. J Psychoactive Drugs. 2000;32(2):211-20. doi: 10.1080/02791072.2000.10400231. [PubMed: 10908010].

15. Koob GF, Le Moal M. Review. Neurobiological mechanisms for opponent motivational processes in addiction. Philos Trans R Soc Lond B Biol Sci. 2008;363(1507):3113-23. doi: 10.1098/rstb.2008.0094. [PubMed: 18653439].
16. Newton TF, De La Garza R2, Kalechstein AD, Tziortzis D, Jacobsen CA Theories of addiction: methamphetamine users' explanations for continuing drug use and relapse. Am JAddict. 2009;18(4):294-300. doi: 10.1080/10550490902925920. [PubMed: 19444733].

17. Robinson TE, Berridge KC. Review. The incentive sensitization theory of addiction: some current issues. Philos Trans R Soc Lond B Biol Sci. 2008;363(1507):3137-46. doi: 10.1098/rstb.2008.0093. [PubMed: 18640920].

18. Srisurapanont M, Ali R, Marsden J, Sunga A, Wada K, Monteiro M. Psychotic symptoms in methamphetamine psychotic in-patients. Int $J$ Neuropsychopharmacol. 2003;6(4):347-52. doi: 10.1017/S1461145703003675. [PubMed: 14604449].

19. Klee H. Amphetamine misusers in contemporary Britain: The emergence of a hiddenpopulation: International Perspectiveson Current trends. In: Klee H, editor. Amphetamine Misuse. Amsterdam: Harwood Academic Publishers; 1997.

20. Gossop MR, Bradley BP, Brewis RK. Amphetamine withdrawal and sleep disturbance. Drug Alcohol Depend. 1982;10(2-3):177-83. doi 10.1016/0376-8716(82)90010-2. [PubMed: 7166130].

21. Srisurapanont M, Jarusuraisin N, Jittiwutikan J. Amphetamine withdrawal: I. Reliability, validity and factor structure of a measure. Aust N Z J Psychiatry. 1999;33(1):89-93. doi: 10.1046/j.1440-1614.1999.00517.x. [PubMed: 10197890].

22. Churchill AC, Burgess PM, Pead J, Gill T. Measurement of the severity of amphetamine dependence. Addiction. 1993;88(10):1335-40. doi: 10.1111/j.1360-0443.1993.tb02019.x. [PubMed: 8251870].

23. McGregor C, Srisurapanont M, Jittiwutikarn J, Laobhripatr S, Wongtan T, White JM. The nature, time course and severity of methamphetamine withdrawal. Addiction. 2005;100(9):1320-9. doi: 10.1111/j.1360-0443.2005.01160.x. [PubMed: 16128721].

24. McGregor C, Srisurapanont M, Mitchell A, Longo MC, Cahill S, White JM. Psychometric evaluation of the Amphetamine Cessation Symptom Assessment. J Subst Abuse Treat. 2008;34(4):443-9. doi 10.1016/j.jsat.2007.05.007. [PubMed:17629443].

25. World Health Organization. Process of translation and adaptation of instruments. World Health Organization; 2010.

26. Waltz CF, Strickland OL, Lenz ER. Measurement in nursing and health research. Springer Publishing Company; 2010.

27. Bagheri M, Mokri A, Khosravi A, Kabir K. Effect of Abstinence on Depression, Anxiety, and Quality of Life in Chronic Methamphetamine Users in a Therapeutic Community. Int J High Risk Behav Addict. 2015;4(3). e23903. doi: 10.5812/ijhrba.23903. [PubMed: 26495258].

28. Zorick T, Nestor L, Miotto K, Sugar C, Hellemann G, Scanlon G, et al. Withdrawal symptoms in abstinent methamphetaminedependent subjects. Addiction. 2010;105(10):1809-18. doi:10.1111/j.13600443.2010.03066.x. [PubMed: 20840201].

29. Elkashef A, Vocci F, Hanson G, White J, Wickes W, Tiihonen J. Pharmacotherapy of methamphetamine addiction: an update. Subst Abus. 2008;29(3):31-49. doi: 10.1080/08897070802218554. [PubMed: 19042205].

30. Hartz DT, Frederick-Osborne SL, Galloway GP. Craving predicts use during treatment for methamphetamine dependence: a prospective, repeated-measures, within-subject analysis. Drug Alcohol Depend. 2001;63(3):269-76. doi: 10.1016/S0376-8716(00)00217-9. [PubMed: 11418231].

31. Rawson RA, Huber A, Brethen P, Obert J, Gulati V, Shoptaw S, et al. Status of methamphetamine users 2-5 years after outpatient treatment. J Addict Dis. 2002;21(1):107-19. doi: 10.1300/J069v21n01_09. [PubMed: 11831496].

32. Watson R, Hartmann E, Schildkraut JJ. Amphetamine withdrawal: affective state, sleep patterns, and MHPG excretion. Am J Psychiatry. 1972;129(3):263-9. doi: 10.1176/ajp.129.3.263. [PubMed: 4340897].

33. Glasner-Edwards S, Mooney LJ, Marinelli-Casey P, Hillhouse M, Ang A, Rawson $\mathrm{R}$, et al. Risk factors for suicide attempts in 
methamphetamine-dependent patients. Am J Addict. 2008;17(1):24-7. doi: 10.1080/10550490701756070. [PubMed: 18214719].

34. Leventhal AM, Kahler CW, Ray LA, Stone K, Young D, Chelminski I, et al. Anhedonia and amotivation in psychiatric outpatients with fully remitted stimulant use disorder. Am J Addict. 2008;17(3):218-23. doi: 10.1080/10550490802019774. [PubMed: 18463999]. 